\title{
Wireless Biomedical Sensor Networks: A technology review
}

\author{
Eduardo Freitas, Amândio Azevedo \\ UMa - Universidade da Madeira, Ciências Exatas e da Engenharia \\ Caminho da Penteada 9020-105, Funchal, Portugal \\ eduardo.pereira.freitas@gmail.com; jara@uma.pt
}

\begin{abstract}
The increase in research in the area of Wireless Sensor Networks (WSN) has brought a whole new meaning to medical devices. This is mainly due to advances in microcontroller technologies. WSN are cited as one of the major technologies of this century and hence, their importance in areas such as health, psychology, fire prevention, security and even the military. The great advantage of this technology is the ability to track, monitor, study, understand and act on any particular phenomenon or event. The primary purpose of a wireless health system is transferring reliable data with minimum delay. This review provides a survey of the vast research done on Wireless Biomedical Sensor Networks (WBSN), including experimental and non-experimental investigations and examples from the theoretical and empirical literature. The review incorporates a wide range of purposes: definition of concepts, review of theories, failures and less positive aspects, all seeking to generate a consistent and understandable overview of WBSN. Such systems are already being marketed, while others are still under investigation. It is also the aim of this review to identify the characteristics of WSN applied to healthcare.
\end{abstract}

Keywords: Wireless Biomedical Sensor Networks, Biosensors, Healthcare Telemetry System.

(C) Copyright 2018 Authors - This is an Open Access article published under the Creative Commons Attribution License terms (http://creativecommons.org/licenses/by/3.0). Unrestricted use, distribution, and reproduction in any medium is permitted, provided the original work is properly cited.

\section{Introduction}

Overall, the elderly population is growing and generally getting older. Life expectancy continues to increase with new advances in healthcare. Today, over 850 million people worldwide suffer from chronic diseases and spend up to $85 \%$ of their savings in healthcare plans. It is always better to prevent a disease than to treat it, therefore individual monitoring is required as a periodic activity [1]. The growing population in developed countries leads governments to increase their healthcare budgets, and also presents new challenges to health systems, especially with older people living either on their own or in old age homes [2].

The increase of research in the area of Wireless Sensor Networks (WSN) has brought new opportunities to the development and use of medical devices. The WSN are seen as one of the most important advances in technology this century and hence its importance in areas as diverse as health, psychology, fire prevention, security and the military. The advantage of this technology is the ability to track, monitor, study, understand and act on any particular health related phenomenon or event [3].

Traditionally, healthcare monitoring is performed on a periodic check basis where patients constantly update physicians on their symptoms; the physician checks and makes a diagnosis, then when possible monitors the patient's progress during treatment. In most cases, health monitoring is done by wireless network infrastructures [4]. But the coverage of these network infrastructures has limitations in bandwidth. Therefore, limitations in health surveillance services can lead to problems sending emergency signals from patients to healthcare workers. With WSN, patients can get continuous health monitoring using wireless ad hoc networks which transmit vital signs over short distances. In most systems, the health data of multiple patients may be resent using the wireless multi-jump routing scheme from a base station [4]. New telemedicine systems already use emerging technologies, such as, 802.15 and 802.16, which are 
characterized by distribution networks for medical information providing life-saving services [5].

Wireless sensors can be placed on patients in a hospital or home care setting to gather physiological signals. The correct WSN design depends on accurate traffic models, the selection of the correct model is essential for the correct management of network traffic, network congestion, interference between nodes and the energy expended by each node. Currently, there are no traffic models that represent medical WSN applications [6]. This review discusses the new opportunities related to medical devices that are currently available as a result of the increased research in Wireless Sensor Networks (WSN).

\section{Node Sensor Wireless Networks}

Over the past years, there has been a significant increase in the number of wearable health monitoring devices to measure physiological signals. However, these systems are still limited and they have important restrictions. For example, Holter monitors are used only to collect data, and the data processing and analysis are performed offline. Because of that limitation, the device became impractical for continued monitoring and early detection of medical disorders. Systems with multiple sensors for physical rehabilitation normally have wires between the sensors and the monitoring system which is a restriction to patient's activity and level of comfort [7].

The most recent technology advances in integration and miniaturization of physical sensors, embedded microcontrollers and radio interfaces on a single chip, wireless networking and micro-fabrication, have enabled a new generation of wireless sensor networks suitable for many applications increasing the interest in health monitoring and rehabilitation. Figure 1 summarizes the characteristics that made WBSN possible.

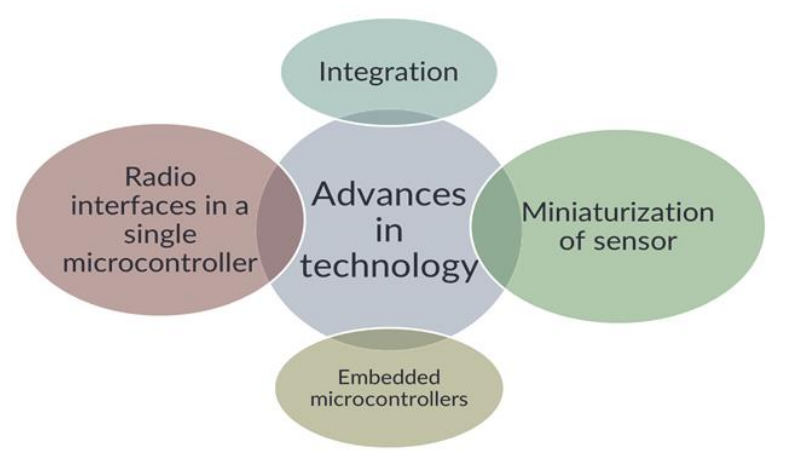

Figure 1. Advances of WSN that made possible WBSN.
The physiological sensors that monitor vital signs, environmental sensors (temperature, humidity, and light), and a location sensor can all be integrated into a Wearable Wireless Body/Personal Area Network (WWBAN) or Wireless Biomedical Sensor Network (WBSN) [7]. Table 1 shows the differences between the WSN and WWBAN.

Table 1. Different challenges faced by WSN and WWBAN [5].

\begin{tabular}{|c|c|c|}
\hline & WSN & WWBAN \\
\hline Scale & $\begin{array}{l}\text { Wide area } \\
\text { coverage }(\mathrm{m} / \mathrm{km})\end{array}$ & $\begin{array}{l}\text { Limited by the human body } \\
(\mathrm{m} / \mathrm{cm}) ;\end{array}$ \\
\hline $\begin{array}{l}\text { Node } \\
\text { number }\end{array}$ & $\begin{array}{l}\text { The huge number } \\
\text { of nodes for } \\
\text { coverage; }\end{array}$ & $\begin{array}{l}\text { The limited number of } \\
\text { pervasive nodes; }\end{array}$ \\
\hline Function & $\begin{array}{ll}\text { Multiple } & \text { sensors, } \\
\text { each } & \text { perform } \\
\text { dedicated tasks; }\end{array}$ & $\begin{array}{l}\text { Single } \quad \text { sensors, each } \\
\text { perform multiple tasks [8]; }\end{array}$ \\
\hline Accuracy & $\begin{array}{l}\text { Compensated by } \\
\text { the redundancy; }\end{array}$ & $\begin{array}{l}\text { Accurate measurements are } \\
\text { required by each node [9]; }\end{array}$ \\
\hline Size & $\begin{array}{l}\text { Small size } \\
\text { preferable but not } \\
\text { a major limitation; }\end{array}$ & $\begin{array}{l}\text { Pervasive monitoring and } \\
\text { need for miniaturization; }\end{array}$ \\
\hline Dynamics & $\begin{array}{l}\text { Exposed } \quad \text { to } \\
\text { extremes in } \\
\text { weather, noise, } \\
\text { and asynchrony; }\end{array}$ & $\begin{array}{l}\text { Exposed to a more } \\
\text { predictable environment; }\end{array}$ \\
\hline $\begin{array}{l}\text { Event } \\
\text { detection }\end{array}$ & $\begin{array}{l}\text { Early adverse } \\
\text { event detection } \\
\text { desirable; failure } \\
\text { often reversible; }\end{array}$ & $\begin{array}{l}\text { Early adverse events } \\
\text { detection vital; human } \\
\text { tissue failure irreversible; }\end{array}$ \\
\hline Variability & $\begin{array}{l}\text { Much more likely } \\
\text { to have a fixed or } \\
\text { static structure; }\end{array}$ & $\begin{array}{l}\text { Biological variation and } \\
\text { complexity means a more } \\
\text { variable structure [10]; }\end{array}$ \\
\hline $\begin{array}{l}\text { Data } \\
\text { Protection }\end{array}$ & $\begin{array}{lr}\text { Lower } & \text { level } \\
\text { wireless } & \text { data } \\
\text { transfer } & \text { security } \\
\text { required; } & \\
\end{array}$ & $\begin{array}{l}\text { High level wireless data } \\
\text { transfer security required to } \\
\text { protect patient information } \\
{[11] \text {; }}\end{array}$ \\
\hline $\begin{array}{l}\text { Power } \\
\text { supply }\end{array}$ & $\begin{array}{lr}\text { Accessible } & \text { and } \\
\text { likely to } & \text { be } \\
\text { changed } & \text { more } \\
\text { easily } & \text { and } \\
\text { frequently; } & \\
\end{array}$ & $\begin{array}{l}\text { Inaccessible and difficult to } \\
\text { replace in implantable } \\
\text { setting; }\end{array}$ \\
\hline $\begin{array}{l}\text { Energy } \\
\text { Scavenging }\end{array}$ & $\begin{array}{l}\text { Solar, and wind } \\
\text { power [9]; }\end{array}$ & $\begin{array}{l}\text { Motion (vibration) and } \\
\text { thermal (body heat) [9]; }\end{array}$ \\
\hline Failure & $\begin{array}{l}\text { Nodes often } \\
\text { disposable [9]; }\end{array}$ & $\begin{array}{l}\text { Difficult replacement of } \\
\text { implanted nodes [9]; }\end{array}$ \\
\hline Access & 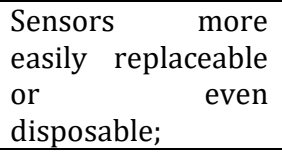 & $\begin{array}{l}\text { Implantable sensor } \\
\text { replacement difficult and } \\
\text { requires biodegradability; }\end{array}$ \\
\hline $\begin{array}{l}\text { Biocompati } \\
\text { bility }\end{array}$ & $\begin{array}{l}\text { Not a } \\
\text { consideration in } \\
\text { most applications; }\end{array}$ & $\begin{array}{l}\text { A must for implantable and } \\
\text { some external sensors. A } \\
\text { chemical reaction with } \\
\text { human tissue that may have } \\
\text { the biosensor. Increase cost; }\end{array}$ \\
\hline Cont & important & Very important, because \\
\hline
\end{tabular}




\begin{tabular}{|l|l|l|}
\hline & WSN & WWBAN \\
\hline Awareness & with static sensors; & physiology is sensitive; \\
\hline $\begin{array}{l}\text { Wireless } \\
\text { technology }\end{array}$ & $\begin{array}{l}\text { Bluetooth, Zigbee, } \\
\text { GPRS, Wireless } \\
\text { LAN, RF; }\end{array}$ & $\begin{array}{l}\text { Low power wireless } \\
\text { required; }\end{array}$ \\
\hline $\begin{array}{l}\text { Data } \\
\text { transfer }\end{array}$ & $\begin{array}{l}\text { Loss of data during } \\
\text { wireless is } \\
\text { compensated by } \\
\text { the number of } \\
\text { sensors used; }\end{array}$ & $\begin{array}{l}\text { Loss of data more } \\
\text { significant, and may require } \\
\text { additional measures to } \\
\text { ensure QoS (Quality of } \\
\text { Signal) and real-time data } \\
\text { interrogation capabilities; }\end{array}$ \\
\hline
\end{tabular}

Personal health devices use standards addressing interoperability, such as weighing scales, blood pressure monitors, and blood glucose monitors. This family of standards is based on a framework defined as IEEE 11073-20601-2008 and its amendment, IEEE 11073- 20601a-2010. The Personal, Home and Hospital Care (PHHC) profile developed by the ZigBee Alliance relies on the on-going work being developed by IEEE 11073 allowing the interoperability with medical devices [12].

\section{Wireless Biomedical Sensor Network}

Advances in technology have allowed the integration and miniaturization of sensors, embedded microcontrollers and radio interfaces in a single microcontroller; WSN and microfabrication have allowed a new generation of WSN suitable for many applications. One of the most exciting and important areas of application is in health supervision.

Information technology companies are aware of the increasing interest and demand for this technology and they are designing m-health solutions such as eWatches or LifeShirts. As a result, wireless sensor network applications to Healthcare present effective commercial solutions for the public and hospital research facilities [2].

\section{1. Measurements in Medical Applications}

Nowadays, everyone desires to know their health status, and because of that, early detection is important, like monitoring disease or a patient's vital signs to survive extreme conditions/situations, but it is important too in everyday life situations. So, there are several parameters/diseases of interest, and the sensors must be able to measure or detect the parameters/diseases. Examples of parameters that currently can be measured are:

- Cancer detection: Today, there is no conclusive evidence on how to prevent cancer, but its detection is possible, and crucial. Studies have shown that cancer cells exude nitric oxide, which affects the blood in the area surrounding a tumour [9].

- Glucose Level Monitoring: Glucose levels can be measured by a biomedical sensor. This method can provide a more consistent, accurate, and less invasive evaluation of diabetes [9].

- Asthma: Sensors can detect allergens in the air and report the status continuously to the physician and/or to the patient. The server also collects information from the network of national monitoring stations of air quality [9].

- Preventing medical accidents: Approximately 98,000 people die every year due to medical error. These deaths occur in hospitals because of medical accidents caused by human errors. The "E-nightingale project" uses wearable environmental sensors in a network to reduce medical accidents and to understand nurses' activities [9].

- Cardiovascular diseases and heart rate monitoring: Sensors can be placed discretely on a patient allowing the physicians to receive the patient's vital information and thus, prepare treatment while monitoring their patient's health. The practice of heart rate monitoring is aimed at saving many lives. Approximately $50 \%$ of fire-fighters die as a result of heart attack [13]. The given medical application allows for monitoring the firefighters working environment and their heart rate, hence determining their potentiality for working in such conditions. The use of chest straps with electrodes can save the lives of many fire-fighters since the electrodes can operate in a moist condition in contact with the chest. The similar application can be achieved using special wrist watches whose effectiveness can only be seen when triggered automatically if any significant adverse conditions arise, or when the start button is pressed. These wrist watches compute the user's blood pressure and heart rate using the oscillometric method. However, it is important to note that there is no approved practical application which one can wear while at a job, and this poses a considerable challenge [14].

- Alzheimer, depression and the elderly: In these situations, it is possible to detect abnormal 
situations, such as falling, and alert neighbors, family or the nearest hospital. It can work with accelerometers to detect these movements and may use the ZigBee protocol or via GSM to provide real-time information. It can also use Radio-Frequency Identification (RFID) readers to control the inputs and outputs of the patient; sound sensors can detect motion and request assistance, light sensors can check the opening of a refrigerator door to monitor how often a patient gets food [15].

- Stroke and post-stroke: According to the Portuguese Stroke Society (Sociedade Portuguesa do Acidente Vascular Cerebral) 3 people per hour in Portugal have a stroke, which is the greatest cause of death in Portugal. In the US stroke affects 700,000 people each year and 275,000 of these people die. Strokes affect cognitive language, perceptual, sensory and motor abilities [9]. The rehabilitation process is long and continues beyond the hospital. Wearable sensors (normally with accelerometers) can be used to monitor home-bound people (like motor behavior in the home and predict some important clinical conditions, such as motor disabilities with hands, arms, legs or other human body parts), and it provides accurate assessments to guide the rehabilitation process [16].

- Epileptic Seizure strike early warning: The University of Chicago Medical Center developed a device (Mobi) that can detect changes in electrical brain signals before a seizure. Signals that are detected by the device transmit a warning to a receiver to protect the patient [17].

- Artificial retina: 100 micro sensors are implanted inside the eye that produce electrical signals. The underlying tissue converts the signals into a chemical response, reproducing the behaviour of normal retinal light stimulation [17].

- Home monitoring: there are many instances in which future medical systems might develop as a result of the applications of WSN. These areas include smart nursing homes, research augmentation, in-home assistance, and in clinical trials. These aspects of monitoring based in homes give the patients the opportunity to manage their dignity and privacy and provides convenience. The ability to receive these services while at home makes the applications practical. WSN make it possible for the smart homecare network and family members to be part of the recognized healthcare team. Home monitoring can help a patient with memory aids and other services related to patient assistance which can balance between the restoration of lost independence and the preservation of safety [18].

- Mobihealth: This is a medical application of the WSN which makes it possible to serve a patient remotely. This is applicable in a situation whereby much clinical research and more informed attention is required to ensure that the health of the patient in question is potentially improved. It ensures that a patient must not necessarily be present in a healthcare unit to receive the prescribed medical attention [19].

These are some of the parameters that can be measured in medical applications; nonetheless, all these measurements can be applied in various situations. The measurement of these parameters is still under development and others need improving to increase the quality of life.

\section{2. Information of interest in Medical Applications}

Another area of interest with respect to WSN is the important information to be extracted from the available systems to be used in medical applications. WBSN is such a concept which is regarded with great significance in this context. WBSN refers to the Wireless Body Area Network (WBAN) and it uses a wireless architecture that consists of several Body Sensor Units (BSUs) combined with a single Body Central Unit (BCU). This network is made up of wearable computing devices which are in development. The WBAN is an onbody sensor and it has high sampling rates leading to significant energy consumption (i.e., low battery life), and the wireless devices inclusion increases the energy consumption. In real time, the situation of several patients is being monitored constantly in this type of architecture. So, it can monitor physiological parameters. However, this type of application faced several challenges when designed. For example, communication between the sensors needs to be reliable and free of interference and it should also provide flexibility to the users. The growth of WBAN 
must include the advance of diagnostic tools of the medical monitoring system [12].

A variety of physiological sensors that monitor vital signs, environmental sensors (temperature, humidity, and light), and a location sensor may be integrated into a WWBAN. The WWBAN is constituted by inexpensive, lightweight and miniature sensors, and it may allow long-term, discrete and ambulatory health monitoring with instantaneous feedback to the user about the current state of health and the user's medical records in real-time. Such a system with a computer can be used to supervise the rehabilitation in multiple conditions, and even provide early detection of medical conditions. For example, intelligent heart monitors can alert patients about their medical condition or provide information to a specialized service following a catastrophic event. When integrated into a broader telemedicine system with the patient's medical records, WWBAN allows for a revolution in medical research by sending all collected data. A large amount of collected physiological data will allow quantitative analysis of various conditions and patterns [7].

Recent advances in miniaturization of intelligent biosensors have opened new opportunities for the continuous monitoring of patients [9]. Unobtrusive tiny wearable sensors collect large amounts of data automatically, reducing the cost and inconvenience of regular visits to the physician [9].

Figure 2 shows how WSN has access to information of interest in Medical Applications.

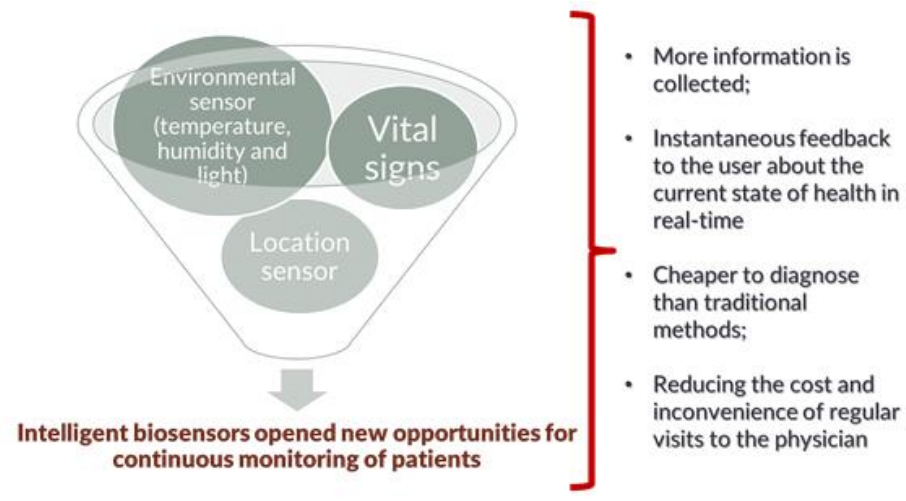

Figure 2. Resume of information of interest in WBSN.

\subsection{WSN used in Medical Applications}

The technologies used in WSN have a wide application and can be applied in almost all health areas, including sensors and positioning systems such as GPS [5]. For example, the wireless data communication is a bidirectional radio frequency communication with ad hoc routing, which allows each patient's node to send the data to a base station, even if they are not within its direct radio range [15] as shown in figure 3.

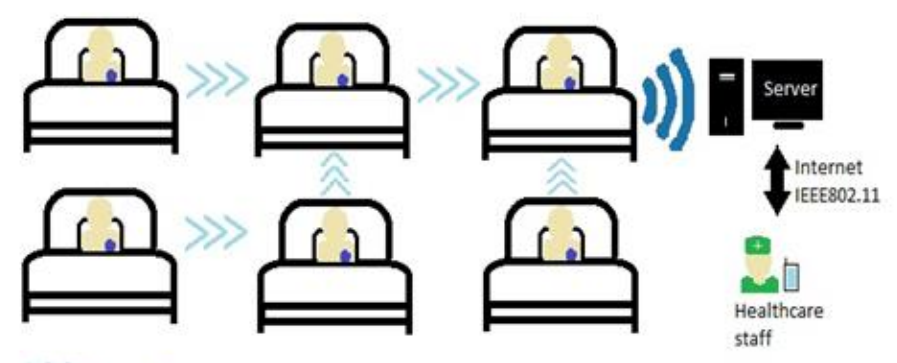

Figure 3. Architecture example of a healthcare system based on a WSN.

Aminian and his team [4] designed a prototype of a health system for hospitals, which is the concept of Ubiquitous healthcare system. This concept is to place non-intrusive wireless sensors on a person's body to form a wireless network that can communicate the patient's health status with the base station connected to the monitoring system. However, the relay nodes (in the middle) do not require the use of a high-frequency band and can transmit the data over a short-range frequency module (RFM). It is important note that reserved medical bands exist, such as the Medical Implant Communication Service (MICS). This band coverages is 10 meters in diameter and operates in the 402-405 MHz frequency band that can be used for body area network applications because of their low power transmissions [4].

Tolentino and his team [20] presented architecture of a ubiquitous health system for continuous monitoring of patients in their natural physiological conditions, or elderly patients with chronic diseases. The biggest difference being, that it is designed to monitor the elderly who live in remote areas or in a small nursing home without enough health technical support, instead of monitoring patients in a hospital environment. By incorporating the wireless sensor this WSN adhoc is integrated with existing medical practices and technology in real-time remote monitoring to alert the medical staff to the patient's health status or to provide medication The system transfers the wireless data to a base station connected to a server on an ad hoc network using IEEE 802.15.4 or LR-WPANs [20]. Sheltami and his colleagues [21] 
developed a telemetry project with the definition of alert priorities depending on the emergency. In this WSN, profiles of patients are updated with the information processed in the central database [21]. The central computer is responsible for sending e-mails and/or messages in case of emergencies [20]. Mbakop and his team [22] developed monitoring of patients in real-time systems, which is made up of a system of two nodes where vital signs are collected and transmitted wirelessly to a base station and then the data is stored and presented on a continuous base station. The great innovation in this design is the correct management of the system, and the biggest challenge is its' actual use in the future, through the patient's movements to produce energy for sensors [22].

Managing memory at home

Home monitoring is one of the examples being developed with WSN, not only to detect environmental parameters that can affect patients but also to help in memory and other healthcare and security services [9]. Gaddam and his team developed and implemented a SMART, which is based on Selective Activity Monitoring (SAM) and integrates various intelligent sensors which communicate via the standard radio protocols. The system depends on a number of selected sets of wireless intelligent sensors and a controller. This controller receives and processes inputs from the sensors. The selected sensors are installed as monitors in televisions, reading lamps and beds, in different locations in a house [23].

Walker and his team [15] showed the need to create a single platform, but robust enough to support a number of complex applications. The fundamental technical contributions of the proposal and the improvements of the platform include: 1) the application of JADE (Java Agent-based Development framework) for the WSN environment, 2) the abstraction of sensors and types of events, 3) a user interface for application development, and 4) architecture used to monitor the application states. This system can monitor patient's behaviour, routine and health, and define actions based on detection of significant events. Different sensors such as: RFID readers placed in doorways can monitor movement; a sound sensor can be used to detect movement or to cries for help; and a light sensor in the refrigerator can detect how often a patient opens the refrigerator to eat [15].

The WearIT@work project was established by the European Commission as an integrated project to investigate "Wearable Computing" as a technology dealing with computer systems integrated in clothing (wearIT@work). One possible application of this project is the rapid availability of patient's medical information at any time. This could result in a reduction in the costs of medical examinations, the power to perform medical evaluations on a daily basis according to the circumstances of patients and in extreme cases could ultimately save a patient's life [5].

Alarm-Net presents preventive healthcare with an adaptable solution for continuous exams over wireless sensors for intelligent medical care, creating a historical record and preserving the privacy of the patient. These sensors can detect small changes through key signals, which humans cannot see, and alert them to heart rate, oxygen levels in the blood and the circadian rhythm indicating possible changes in health requirements [24]. Alarm-Net accomplishes these goals through the unification and aggregation of heterogeneous devices in a common architecture [25].

CodeBlue (developed by Harvard University) is a wireless infrastructure intended to provide a common protocol and software structure in a disaster response scenario, allowing wireless monitoring of patients and rescuers. The CodeBlue is a self-organized platform that is easy to connect because of its ad hoc architecture and that it integrates different nodes of wireless device sensors. The system integrates low-power wireless sensors, and offers services for the establishment of credentials, handoff, location tracking, and network's filtering and aggregating of produced data by the sensor. The simple interface allows emergency medical technicians to request data from a group of patients [24]. The CodeBlue is designed to pass through a wide range of density networks and operates in a range of wireless devices, from the limited resources to the PDA and more powerful PCs. The CodeBlue has several types of sensors (oximetry, ECG and motion sensor) and is used together with the ZigBee trading platforms, Mica2, MICAz, and Telos. Researchers consider that such platforms have a good response in research settings but have many faults in actual scenarios due to the dimensions of the modules and batteries; a support platform has also been developed for lighter sensors to be used in accident monitoring modules in a noninvasive way [26].

Another application, the MEDiSN, similar to CodeBlue, uses a related but different architecture [27]. The value includes a number of physiological monitors (PMs) - nodes on which the physiological patient data is 
collected. Each node has sensors with a configurable frequency, physiological encrypted data, and transmits them to a network of relay points (RPs). The RPs transmit the data to the PMs Gateway and the gateway management data to one or more PMs. To support this traffic in both directions, the RPs auto-configure in a routing tree with PMs in its branches. While RPs are stationary, PMs can be mobile and periodically select the best RP to transmit the data [28].

Moreover, there is the NetCare which serves as a digital campaign which allows those in rural and remote areas to access modern digital technology. It was a Portuguese project developed by Inovamais in partnership with Agilus I+D, the Engineer at the Faculty of Oporto University, São Sebastião Hospital, and Speculum. This project developed a monitoring platform where healthcare services such as emergency vehicles and ambulances were interconnected, and physicians can observe the situation of many patients. This information was available on a web application [29].

Furthermore, AID-N handles mass incidents like accidents. Instead of implementing APs (access policy) on the wall, wireless repeaters are positioned for an emergency course set. When APs are flashing green lights, the medical team is aware of a precise emergency [24]. The system consists of the four blocks MiTags (MiTags are modules and extensible wireless sensor's platforms). These modules support two types of communication: short range, so as to be able to create a WBAN and long range, so it can connect to support a mesh. The platform supports several types of sensors, in particular: blood pressure, temperature, $\mathrm{SpO}_{2}$ (arterial oxygen saturation and others) routers, devices to access the MiTags and a central server [30].

eHit is a Finnish company that provides services and technologies related to healthcare at a distance. It is one of the technologies of the Health Gateway, a platform which connects to a mobile device and a server. The mobile device has the function of collecting data from the sensors and sending it to the server, and the server's aim is to receive data and forward it to be processed. However, the eHit company has more products in its portfolio, including the Patient Care Device Gateway, which is similar to the Health Gateway, but allows monitoring in the hospital without a mobile device, using the LAN connection, as well as theeLink, which is a module connecting sensors without a Bluetooth connection, and thus connected to the mobile device [30].
The HipGuard is a system developed for patients who are recovering from hip replacement surgery. This system monitors the patient's leg and hip position and rotation with wireless sensors. The alarm signals are sent to the patient's wrist unit. If his hip and leg positions or rotations are false, the HipGuard system provides useful information in real time for the patient's rehabilitation process [17].

Artificial retina uses smart sensors and an integrated microsystems (SSIM) project. This prosthesis is formed with 100 microsensors, constructed and implanted in the human eye. Wireless communication is used to meet the need of control, image identification and validation. As these sensors produce electrical signals the underlying tissue converts the signals into a chemical response, and thus simulates the retinal behaviour with stimulation by light [9].

The Psychology Department of the Georgia Institute of Technology, more specifically, the Georgia Tech Sonification Lab, also addressed problems in vision. They created the SWAN project, a practical and portable device which features navigation software for people without vision or even in places where vision is limited, by emphasizing the need to avoid obstacles or certain environmental characteristics quickly [5].

\section{Other Systems used in Healthcare}

For the detection of vital signs and various physiological data various technologies have been developed: Vital Signs Monitoring System [31], LifeShirt, Fireline [32], UbiMon [32], Satire Project [24], SMART, HealthGear, MobiHealth/Mobicare, CareNet, Jacket Vital, BikeNet, eWatch, AMON project [33], MagIC System [33], Smart Vest [34], Secure Mobile Computing using Biotelemetrics [32] and Armband SenseWear [35].

Another technology that has been used is the endoscopic capsule. This method for recording images of the digestive tract used in medicine allows a small chamber the size of a tablet to show images of the inside of the gastrointestinal tract, making it possible to check areas where using the traditional forms of endoscopy are impossible [33].

One of the areas which has aroused more interest among researchers is the area of monitoring babies, not only because it's a lucrative area, but also due to the growing concern and need to help prevent sudden infant death syndrome (SIDS). For that, the invention SleepSafe monitors the child's sleeping position and alerts parents [34]. Another solution is the Baby Glove, 
this project is to protect premature infants, as they are subject to various health risks [36].

The use of WSN in biomedical applications facilitates the development of wearable systems, making them lighter and less obtrusive for the elimination of cables. The wearable systems are computer systems integrated into consumer items used as garments. Therefore, a need exists to respond to various aspects:

- The insertion of mechanisms and policies to reduce energy consumption and increase the durability of the monitoring and detection of the data collected by the sensors;

- Development of a protocol to provide biomedical signals in a database on the Internet, where data would be accessed by physicians. Thus, there would be several advantages, such as a quicker realization of exams, and providing of reliable data, cost reduction and convenience in carrying out the examinations;

- In the study and implementation of mechanisms for authentication and information security [14].

In terms of protocols, several issues such as robustness, security, and communication without interference are key requirements. It is believed that the role of wireless sensor networks in medicine can be expanded further. In the near future, smart spaces incorporated with wireless sensor networks can detect environmental conditions and take preventive measures based on that knowledge. The system can achieve ubiquity, where each one will have a computational module capable of interacting with the system of the smart area and avoid health problems.

\section{Conclusion}

After reviewing several articles and the research conducted, we may conclude that there is still a long way to go in the area of wireless sensor networking. Existing medical applications based on sensor networks are in the first-line of research for use in the near future and medical device will start to use this technology to improve their capabilities. Security issues are a significant concern and there is still a number of other large challenges to overcome.

The future should include specialized medical technology with WSN, where the existing infrastructures enhance the collection of data in real time, in which medical care at home and smart homes are improved. Also, the constant collection of clinical data of patients will reduce, significantly, the costs of tests and regular visits to physicians. Another important point in the future will be the relationship between bioscience, biotechnology and nanoscience (nanotechnology) in the development of sensors.

\section{References}

[1] A. Minaie, A. Sanati-Mehrizy, P. Sanati-Mehrizy and R. Sanati-Mehrizy, "Application of Wireless Sensor Networks in Health Care System," in 120th ASEE Annual Conference \& Exposition, 2013.

[2] P. Neves, J. Fonseca and J. Rodrigues, "Simulation Tools for Wireless Sensor Networks in Medicine: A comparative study," Biodevices, 2008.

[3] T. Camilo, A. Rodrigues, J. S. Silva and F. Boavida, "Redes de Sensores Sem Fios, considerações sobre a sua instalação em ambiente real," Universidade de Coimbra, Portugal, pp. 89-98.

[4] M. Aminian and H. Naji, "A Hospital Healthcare Monitoring System Using Wireless Sensor Networks," Health \& Medical Informatics, vol. 4, 2013.

[5] C. Lozano, C. Tellez and O. Rodríguez, "Biosignal Monitoring Using Wireless Sensor Networks," in Biomedical Engineering, Trends in Electronics, Communications and Software, 2011.

[6] G. G. Messier and I. G. Finvers, "Traffic Models for Medical Wireless Sensor Networks," IEEE Communications Letters, vol. 11, pp. 13-15, 2007.

[7] A. Milenkovic, C. Otto and E. Jovanov, "Wireless Sensor Networks for Personal Health Monitoring: Issues and an Implementation," The University of Alabama in Huntsville, USA, 2006.

[8] P. Honeine, F. Mourad, M. Kallas, H. Snoussi, H. Amoud and C. Francis, "Wireless sensor networks in biomedical: Body Area networks," in $7^{\text {th }}$ International Workshop on Systems, Signal Processing and their Applications (WOSSPA), 2011.

[9] P. Neves, M. Stachyra and J. Rodrigues, "Application of Wireless Sensor Networks to Healthcare Promotion," Journal of Communications Software and Systems, vol. 4, no. 3, pp. 181-189, 2008.

[10] M. Barua, M. Alam and L. X. Xiaohui, "Secure and quality of service assurance scheduling schem for WBAN with application to eHealth," in Wireless Communications and Networking Conference, 2011.

[11] A. Darwish and A. E. Hassanien, "Wearable and Implantable Wireless Sensor Network Solutions for 
Healthcare Monitoring," Sensors, pp. 5561-5595, 2011.

[12] H. F. López, "Remote Vital Signs Monitoring Based on Wireless Sensor Networks," 2011.

[13] S. N. Kales, E. S. Soteriades, S. G. Christoudias and D. C. Christiani, "Firefighters and on-duty from coronary heart disease: a case control study," Environmental Health: A Global Access Science Source, 2003.

[14] C. Baker, K. Armijo, S. Belka, M. Benhabib, V. Bhargave, N. Burkhart, A. Minassians, G. Dervisoglu, L. Gutnik, M. Haick, C. Ho, M. Koplow, J. Mangold, S. Robinson, M. Rosa, M. Schwartz, C. Sims, H. Stoffregen, A. Waterbury and E. Leland, "Wireless Sensor Networks for Home Health Care," in 21st International Conference on Advanced Information Networking and Applications Workshops, 2007.

[15] Z. Walker, M. Moh and T.-S. Moh, "Development Platform for Wireless Sensor Networks with Biomedical Applications," IEEE, pp. 768-772, 2007.

[16] T. Hester, R. Hughes, D. M. Sherrill, B. Knorr, M. Akay, J. Stein and P. Bonato, "Using Wearable Sensors to Measure Motor Abilities following Stroke," in International Workshop on Wearable and Implantable Body Sensor Networks (BSN 2006), Cambridge, MA, USA, 2006.

[17] P. Khan, M. Hussain and K. Kwak, "Medical Applications of Wireless Body Area Networks," International Journal of Digital Content Technology and its Applications, vol. 3, 2009.

[18] C. Gong, "Design and evaluation of a wireless CMOS energy harvester for biomedical sensor networks," International Journal of Microwave and Wireless Technologies, vol. 9, no. 3, pp. 529-535, 2015.

[19] I. Umay and B. and Fidan, "Adaptive Wireless Biomedical Capsule Tracing Based on Magnetic Sensing," International Journal of Wireless Information Networks, vol. 24, no. 2, pp. 189-199, 2017.

[20] R. Tolentino, Y. Kim, B. Park and G. Park, "A Design and Analysis Ubiquitous Healthcare Monitoring System over Wireless Sensor Network," International Journal of Multimedia and Ubiquitous Engineering, vol. 6, pp. 55-69, 2011.

[21] T. Sheltami, A. Mahmoud and M. Abu-Amara, "An Ad hoc wireless sensor network for Telemedicine applications," The Arabian Journel for Science and Engineering, vol. 32, pp. 131-143, 2006.
[22] A. Mbakop, A. Lambebo, L. Jayatilleke and S. Haghani, "Implementation of a Wireless Body Area Network for Healthcare Monitoring," ASEE American Society for Engineering Education.

[23] A. Gaddam, C. Mukhopadhyay and G. S. Gupta, "Elder Care Based on Cognitive Sensor Network," IEEE Sensors Journal, vol. 11, pp. 574-581, 2011.

[24] N. Fatema and R. Brad, "Security Requirements, Counterattacks and Projects in Healthcare Applications Using WSNs - A Review," International Journal of Computer Networking and Communication (IJCNAC), vol. 2, 2014.

[25] J. Stankovic, A. D. Wood and T. He, "Realistic Applications for Wireless Sensor Networks," Theoretical Aspects of Distributed Computing in Sensor Networks. Monographs in Theoretical Computer Science. An EATCS Series. Springer, Berlin, 2011.

[26] M. Welsh, Wireless Sensor Networks for Emergency Medical Care, Harvad University, 2004.

[27] J. Ko, C. Lu, M. B. Srivastava and J. A. Stankovic, "Wireless Sensor Networks for Healthcare," Proceedings of the IEEE, pp. 1947-1960, 2010.

[28] J. Ko, J. H. Lim, R. Musaloiu-e., A. Terzis, G. M. Masson, T. Gao, W. Destler, L. Selavo and R. P. Dutton, "MEDiSN: Medical Emergency Detection in Sensor Networks," ACM Transactions on Embedded Computing Systems, vol. 10, 2010.

[29] J. P. S. Oliveira, "Desenvolvimento e integração de sensores numa Plataforma para sistemas de Monitorização Pessoais," Porto, 2012.

[30] S. Leroux, "Convergência entre dispositivos móveis e redes de sensores sem fios," 2013.

[31] S. Stankovic, "Medical Applications Based on Wireless Sensor Networks," pp. 19-23, 2009.

[32] P. Gonçalves, "Monitorização Remota de Pacientes em Ambulatório," Porto, 2008.

[33] M. Rienzo, F. Rizzo, G. Parati, G. Brambillan, M. Ferratini, P. Castiglioni, P. Meriggi, P. Mazzoleni and B. Bordoni, "MagIC system," IEEE Engineering in Medicine and Biology Magazine, vol. 28, pp. 3540, 2009.

[34] BodyMedia, Inc., "SenseWear - Learn More," [Online]. Available: http://sensewear.bodymedia.com/SW-Learn-

More/How-SenseWear-Works

[35] P. Pandian, K. Mohanavelu, K. P. Safeer, T. M. Kotresh, D. T. Shakunthala, P. Gopal and V. C. Padaki, "Smart Vest: wearable multi-parameter remote physiological monitoring system," Medical engineering \& physics, vol. 30, pp. 466-477, 2008. 
[36] S. Rajasekaran, P. Kumuran, G. Premnath and M. Karthik, "Human Health Monitoring using wireless sensors network," International Journal of Application or Innovation in Engineering Management, vol. 2, pp. 323-330, 2013.

[37] J. Stankovic, Q. Cao, T. Doan, L. Fang, Z. He, R. Kiran, S. Lin, S. Son, R. Stoleru and A. Wood, "Wireless Sensor Networks for In-Home Healthcare: Potential and Challenges".

[38] W.-Y. Chung, "Ubiquitous Healthcare System Based on a Wireless Sensor Network," Oulu University Press, Oulu, 2009.

[39] E. M. Gutiérrez, A. F. Rocha, T. M. G. Andrade, D. R. França and H. S. Carvalho, Redes de Sensores Sem Fios, considerações sobre a sua instalação em ambiente real, Coimbra.

[40] A. Bideaux, B. Zimmermann and S. a. S. W. Hey, "Synchronization in wireless biomedical-sensor networks with Bluetooth Low Energy," Current directions in Biomedical Engineering, vol. 1, no. 1, 2015.

[41] Spanakis, V. Sakkalis, K. Marias and Traganitis, "Cross Layer Interference Management in Wireless Biomedical Networks," Entropy, vol. 16, no. 4, pp. 2085-2104, 2014. 